\title{
Improvement of the operation processes of electrotechnology wastewater treatment systems under the energy efficiency criterion
}

\author{
Vladimir Shtepa ${ }^{1}$, Nataliia Zaiets ${ }^{2}$, Nataliia Lutska ${ }^{3}$, Igor Elperin ${ }^{3}$ \\ 1 - Polessky State University, Pinsk, Republic Belarus \\ 2 - National University of Live and Environment Sciences of Ukraine, Kyiv, Ukraine \\ 3 - National University of Food Technologies, Kyiv, Ukraine
}

Keywords:

Wastewater

Treatment

Control

Efficiency

Article history:

Received

21.12.2019

Received in

revised form

04.09.2020

Accepted

30.09.2020

Corresponding

author:

Nataliia Lutska

E-mail:

lutskanm2017@

gmail.com

DOI:

10.24263/2304-

974X-2020-9-3-

15

\section{Abstract}

Introduction. The research is conducted to justify of substantiating scientific foundations for the functioning of electrotechnological wastewater treatment systems of continuous production.

Materials and methods. The approaches towards the creation of technical specifications for continuous production are being analyzed, taking into consideration the criteria of energy efficiency. The study is based on the methods of active and passive experiments on pilot plants and industrial equipment, the methods of cross-effects of water purification methods, the methods of the dominant dynamic pollutant, the modeling concept based on the notations of the universal modeling language UML for efficient processing of measurement information.

Results and discussion. The architecture of the control system with adaptive adjustment of control strategies in real time is substantiated. The system makes it possible to make decisions under conditions of disturbances of natural and man-made origin, taking into account the criterion of energy efficiency. The generalized system includes: a local control system and a decision subsystem with an input signal filtering unit (the decision subsystem contains a block for adaptive formation of control strategies in real time based on Kohonen self-organizing maps). Practically implemented approaches to the object-oriented creation and implementation of technological regulations for combined electrotechnological systems for wastewater purification of continuous production. This made it possible to improve the energy efficiency of multicomponent effluent purification processes for a meat processing enterprise deviating the energy efficiency criterion from zero $\pm 9.6 \%$, and small metallurgy $\pm 3.4 \%$. The synthesis method of object-oriented technological regulations was further developed to improve the control algorithms for combined electrotechnological water purification systems of continuous production based on the energy efficiency criterion, based on assessing the efficiency of using energy resources as an integral parameter for the removal of pollutants from effluents. Intelligent energyefficient control of the process of removing the contaminants from wastewater is being realized through the synthesis of software and information control of the combined electrotechnology wastewater purification systems based on the object-oriented technical specifications for operation.

Conclusion. An improved method for managing the operation of electrotechnological wastewater treatment systems for continuous production ensures compliance with the requirements for the efficient use of energy resources and environmental safety. 


\section{Introduction}

The use of technical and technological solutions to ensure the processes of wastewater treatment are to provide peculiar valid technological modes for the operation of such systems and meet the requirements of environmental safety and quality of wastewater purification [1, 2]. Establishing a relationship between energy consumption levels and the quality of wastewater treatment appears to be an individual task in the formation of the resource allocation for the operation of the industrial wastewater purification systems.

Increased efficiency is achieved by improving the technological regulations for the appropriate complex of equipment for wastewater purification based on the current water passport of the enterprise [3]. The sequence of creating the requirements documents, as universal decisions, is to be based on permanent, temporary, non-recurrent technical specifications (TS) as well as the peculiarities of operation of the specific equipment, which is currently installed at the enterprises.

Wastewater differs from each other in the type and concentration of pollution, the rate of entry and other factors. Based on the multicomponent nature of wastewater, the following basic methods of wastewater purification exist [3-6]: mechanical (physical) methods, chemical methods, physical and chemical methods, biological methods, combined methods. However, the common drawbacks of such methods is that it is necessary to monitor dozens of parameters of water quality and technological processes in real time.

Only industrial units of automated measuring instruments exist and operate reliably at continuous production $[7,8]$ : temperature, pressure, turbidity, flow rates, $\mathrm{pH}$, redox potential, biological oxygen consumption, chemical oxygen consumption, absorption of chlorine, ionic composition. Other studies can only be carried out in laboratory conditions - these include express methods, since there is still a time delay from sampling to transmitting information to technological equipment. Moreover, when designing water purification systems, the possibility of emergency situations of industrial and natural origin is not taken into account, which is necessary for efficient and rational nature management [9]. The task of creating complex criterion for evaluating the performance of systems remove contaminants from aqueous solutions and energy costs for its implementation was not solved by any of the researchers.

Moreover, all the described modern methods of removing pollutants from wastewater require the use of electrical systems (in which the conversion of electrical energy to other types of energy with the simultaneous implementation of technological processes) [10]. There are effective methods of water purification, however, due to the lack of the necessary list of measuring complexes, they work either environmentally dangerous or with the redeployment of resources.

There are a large number of publication devoted to the design and study of mathematical models of electrode [15] and electro-membrane systems for removing pollutants from aqueous solutions [16]. An analytical study of wastewater purification from organic pollution in bioreactors-aerotanks with suspended and fixed biocenosis was carried out, which made it possible to optimize the work of biological water purification methods [17]. Separately, the direction of creating mathematical models of technological equipment is highlighted, which in the future will be the basis of automated control systems $[18,19]$. Each of the options for modeling water purification processes has both advantages and disadvantages [20,21]. But only a combination of physical and mathematical modeling of the processes of removing pollutants from aqueous solutions and the theory of automatic control in a single scientific method will allow integrating the strengths of the approaches and minimizing weaknesses. 
That is why improving approaches to the creation and functioning of electrotechnological wastewater purification systems and reducing their total energy consumption is an urgent scientific and practical task [11]. This situation is also stimulated by the fact that drainage and water purification systems are developing at a rapid pace (an annual increase in their productivity of $4-5 \%$ ) [12, 13].

The research is conducted to justify of substantiating and creating scientific foundations for the functioning of electrotechnological wastewater purification systems of continuous production, the functioning of which will meet the requirements of the efficient use of energy resources and environmental safety.

\section{Materials and methods}

\section{Materials}

The object of research is electrotechnological wastewater purification systems for continuous production on the example of a meat processing enterprise and a minor metallurgy enterprise.

For the achievement of the put aim the work uses the methods of active and passive experiments on pilot plants and industrial equipment, the methods of cross-effects of water purification methods, the methods of the dominant dynamic pollutant, the modeling concept based on the notations of the universal modeling language UML for efficient processing of measurement information. The modern approaches towards the creation of technical specifications for continuous production are being analyzed, taking into consideration the criteria of energy efficiency.

\section{Methods}

\section{Research plan}

The research includes stages:

- Substantiation of the improvement of methods for creating technological regulations for wastewater purification systems based on the criterion of energy efficiency;

- Substantiation of methods for improving the functioning of electrotechnological wastewater purification systems based on effective processing of measurement information;

- Development of a model of a water purification process control system when processing measurement information in real time;

- Experimental study of the created control system for electrotechnological water purification at a meat processing plant;

- Analysis of the research results of electrotechnological water purification systems for continuous production for compliance with the requirements for the efficient use of energy resources. 


\section{systems}

Methods for creating technological regulations for wastewater purification

Improvement of the TS for the combined electrotechnology wastewater purification of the continuous production is based on the use of familiar basic methods [21, 22], taking into account the technological scheme and elimination modes for the potential natural and mancaused emergency situations, nomenclature and operation modes for wastewater purification equipment on the basis of complex acknowledgement of investments efficiency and energy efficiency levels in particular (Figure 1).

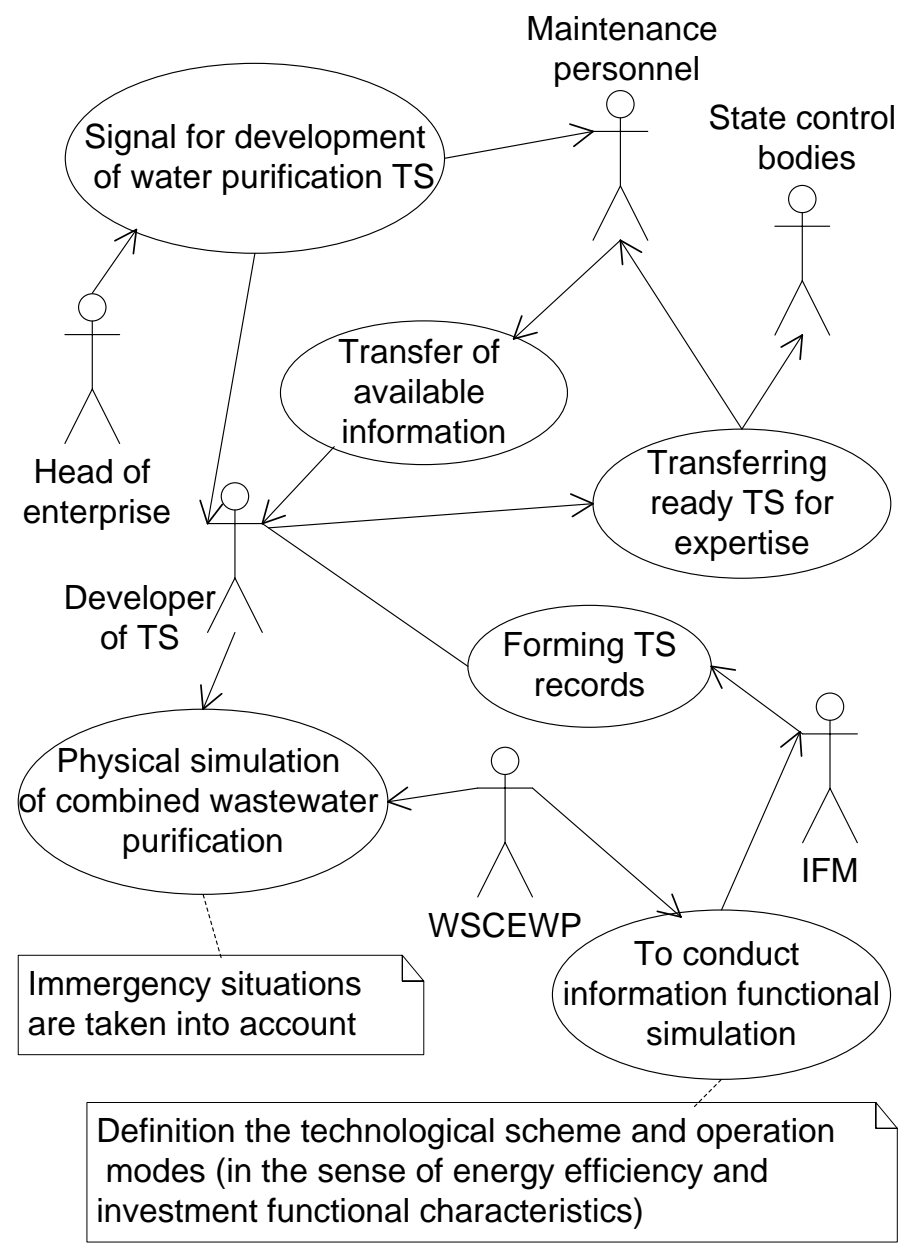

Figure 1. The building and logical scheme for the creation of the TS for the combined electrotechnology wastewater purification of the continuous production (UML notes) 
Method of improving the functioning of electrotechnological wastewater purification systems based on effective processing of measurement information

Stages of modeling the impact of emergency situations when setting up equipment for wastewater purification $[1,9,11]$ :

- When creating model solutions before treating water with the use of working standard of the combined electrotechnology wastewater purification by adding the contaminants with exceeding values which are recorded in the water passport of a particular enterprise;

- When forming the knowledge base for the synthesis of the simulation modeling neural network.

The object-oriented logical sequence of the advanced TS synthesis method includes a number of steps (Figure 2) [1, 11].

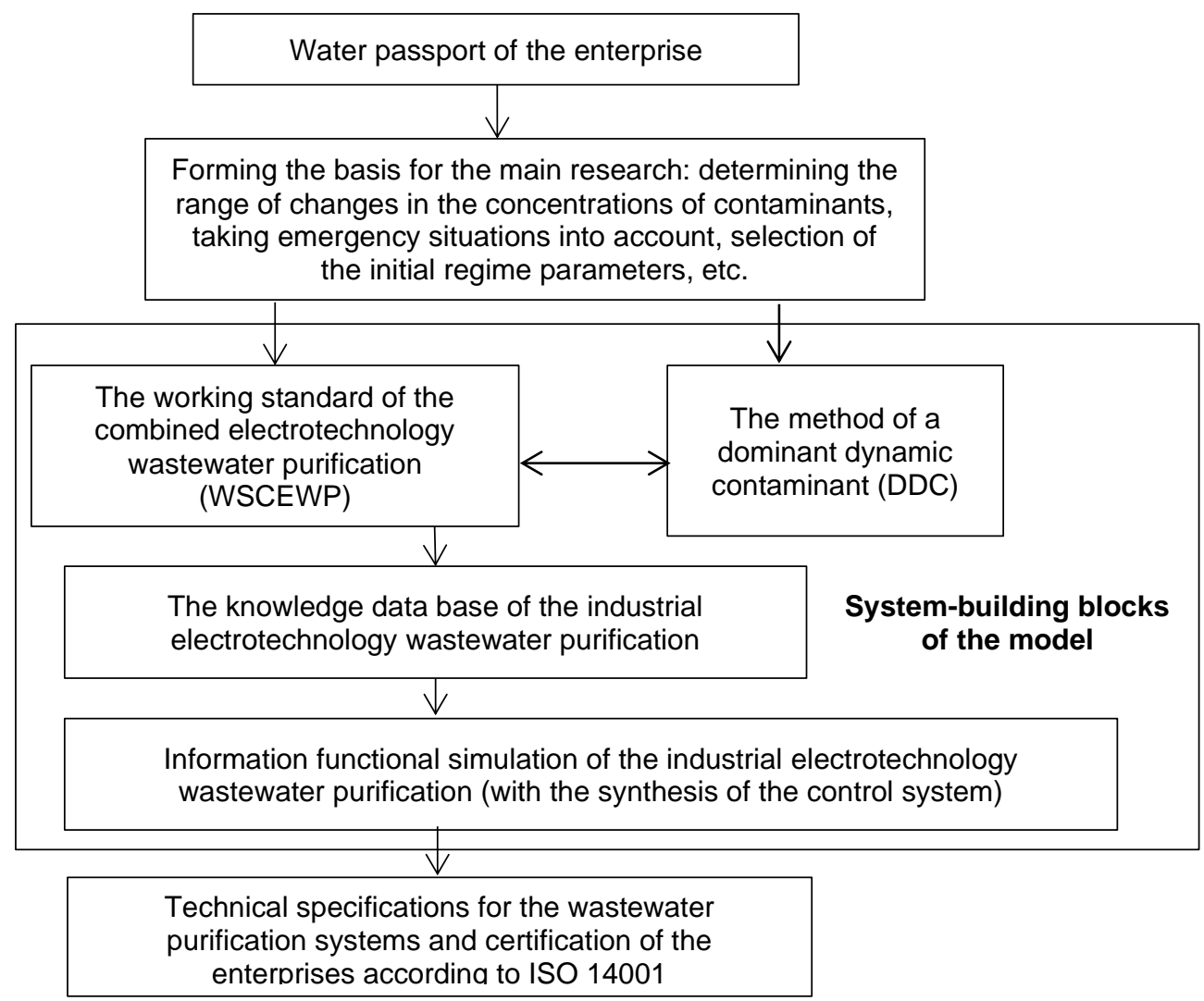

Figure 2. Logical model of the TS synthesis on the basis of an effective obtaining and processing of measurement information taking into account the effect of emergency situations 


\section{Cross-effect of different water purification methods}

An analysis of the operation of purification systems, in the case of a combination of basic methods [24], showed the superposition of the action of different equipment on the same pollutants. On the basis of the results obtained, the sequence of creation of water purification systems with the expansion of functional capabilities and their ability to effectively counteract emergency situations is justified - the cross-effect of methods for removing pollutants from effluents.

The key tasks for the practical implementation of the method of cross-effects are: the availability (development) of tools that would provide research on water purification in real time; establishing a limiting environmental criterion that would take into account the resource consumption for water purification.

\section{Dominant dynamic pollutant method}

At the stage of analyzing the quality of wastewater purification of real enterprises and model solutions [23], a hypothesis arose that in order to remove some pollutants, it is necessary to first eliminate other pollutants, which critically reduce the removal effect of the former. Taking into account the research results, it was concluded that it is rational to propose the use of the dominant dynamic pollutant (DDS) method. That is, DDS is a multicomponent wastewater pollutant that, given the actual composition of the wastewater, must be removed first. The technical and economic modes of its elimination have been determined by the method of cross-effects. The presence of the next DDS is assessed and removed, and these steps are iteratively repeated to meet regulatory requirements for effluent quality.

\section{Processing of research results}

According to the Kolmogorov (Kolmogorov-Smirnov) criterion, the possibility of using parametric approaches of mathematical statistics was established [28]. Verification of compliance with the normality requirements of the law of distribution of random variables with an analysis of the presence of outliers in the information received at enterprises. The nonparametric approach and analysis of the Mann-Whitney test results are applied for all pairs of production approbation samples (Jonkhier U) statistics.

\section{Results and discussion}

\section{Forming generalizing criterion of efficiency}

Analysis of the logical model (see Figure 2) indicates (system-building blocks) that the key element for creating the TS is the development of a complex criterion for the efficiency evaluation of the use of electrotechnology wastewater purification means [25]. Herewith, technical efficiency $(P)$ is calculated by the following formula:

$$
P=\frac{\left(C_{\text {in }}-C_{\text {out }}\right)}{C_{\text {in }}} \cdot 100 \%,
$$

where $C_{\text {in }}$ is the value of the quality of wastewater under purification, and $C_{\text {out }}$ is the concentration of contaminants after purification. 
However, this approach to determining the efficiency takes into account the environmental component only, without considering the performance data which characterize the operation of the technological equipment. Taking into account the considerations presented in [4], it is apparent that the provision of a given level of wastewater purification can be implemented with various energy costs. Only comprehensive assessment of the operational efficiency of the technological equipment of wastewater purification will make it possible to find the boundaries of efficient energy resources use. On the basis of the conducted theoretical research and experimental tests [2-4] the basic criterion of energy efficiency has been obtained as follows:

$$
E F_{Y}=\frac{\left[\left(\frac{L 1_{\text {out }}-L 1_{\text {ref }}}{L 1_{\text {out }}} \cdot 100 \%\right)+\ldots+\left(\frac{L N_{\text {out }}-L N_{\text {ref }}}{L N_{\text {ref }}} \cdot 100 \%\right)\right] \cdot \sum_{i=1}^{N} Q_{i}}{\sum_{i=1}^{N} W_{i}} \% / \mathrm{kWh},
$$

where $L_{\text {out }}$ is the actual value of the corresponding wastewater purification quality assessment parameter; $L_{r e f}$ is a given (specified) value of the corresponding wastewater purification quality assessment parameter; $Q$ is the equipment operating time in hours; $W$ stands for electricity consumed by the electrotechnology wastewater purification equipment in $\mathrm{kWh} ; N$ is the number of wastewater purification quality assessment parameters (they generally correspond to the number of plants involved into the wastewater purification process).

Technologically, the task of controlling the combined wastewater purification system is in maintaining the value of the energy efficiency criterion (2) close to zero: if $E F_{Y}>0$, the purification is unsatisfactory, if $E F_{Y}<0$, the use of energy resources is inefficient.

\section{Justification intelligent control system}

Automated information-measuring complexes of water purification systems, with the maximum layout for solving control problems can be divided into levels [2,6]:

- the first level - means of obtaining information about the parameters of the technological control object (sensors);

- the second level - primary analysis devices (in some cases, the sensors and organs are inseparable - control actions from sensor regulators can be formed);

- the third level - means of centralized processing of information from sensors and regulators, as well as additional external information, for example, adaptive control algorithms and development of solutions for regulators in order to optimize the processes of obtaining specified quality criteria, including on economic requirements;

- the fourth level - a centralized control system for a whole complex of technological objects, provides control over the work of local systems of the third level, a statistical analysis of the quality indicators of individual units and the development on this basis of optimal (effective) solutions for specific third-level systems.

As a result of the research, the architecture of the control system with adaptive real-time control strategy adjustments with the possibility of making decisions under the effects of natural and man-caused disturbances, taking into account the energy efficiency criterion (2), has been developed. The generalized system includes a local control system and a decisionmaking subsystem with an input signal filtering unit (the decision-making subsystem contains a unit of adaptive real-time control strategy building based on Kohonen Selforganizing map). 
The wastewater purification and wastewater purification equipment control system consists of a decision-making subsystem 1 , which includes an input signal filtering unit 2 , a unit for the neural network correction of fuzzy cognitive map (FCM) concepts 3; a decisionmaking unit 4 , a unit of real-time adaptive forming of control strategies 5 , a control unit 6 ; a local control system 7 consisting of a local automatic control device 8 , actuators 9 (electrolyzer, pumps, vacuum pumps, valves, heaters, compressors, etc.), a control object 10 (Figure 3). ICP DAS i-8417 PLC-class microcontroller (upper level), ATmega128-16AU microcontroller (lower level) [6] have been selected as control devices for the implementation of the instrumental information and measurement complex of the combined electrotechnology wastewater purification. $\mathrm{C}++$ programming software has been developed for these technical automation means with the use of the QT library in the Qt Creator programming environment.

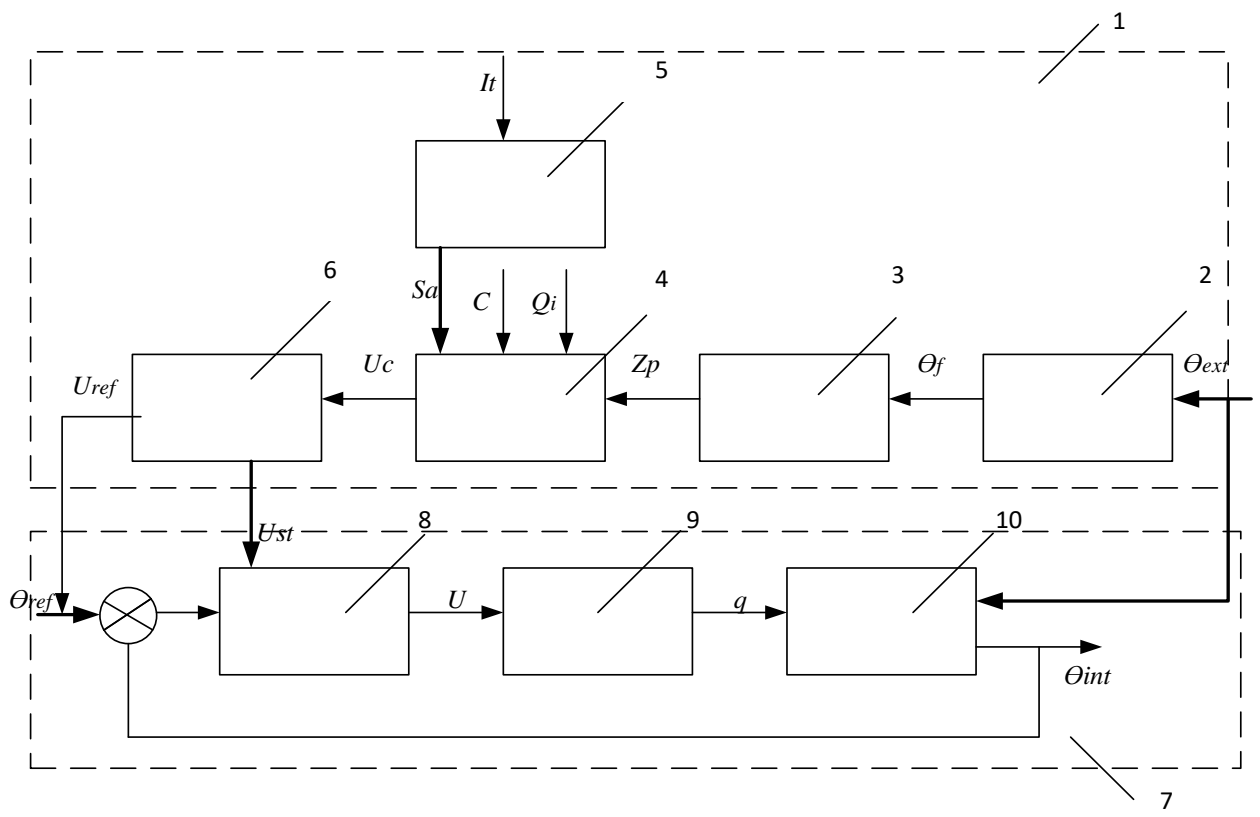

Figure 3. Architecture of the intelligent system of energy efficient control of the combined electrotechnology wastewater purification:

$\theta_{\text {ext }}$ - signal from the sensing elements;

$\theta_{f}-$ stands for the cleared information signals;

$Z_{p}$ - stands for perturbations;

$Q_{i}$ - stands for possible control actions and quality indicators;

$C$ - cost data of the components of the electrotechnology process;

$U_{c}$ - choice of the control strategy;

$U$ - current control strategy;

$I_{t}$ - information entered by process control operators;

$S_{a}$ - updated set of strategies;

$U_{r e f}$ - change in control;

$U_{s t}$ - stands for new images of the control strategy;

$\theta_{\text {ref }}-$ given value for control;

$\theta_{\text {int }}$ - generated control value;

$q$-stands for the influence on the water purification plants. 


\section{Analysis of test results}

The production testing of the control system was conducted at the enterprises of meat processing and minor metallurgy. Water passports and TS were previously developed for such enterprises [20, 26].

On the bases of the use of the working standard of the combined electrotechnology wastewater purification equipment for the meat processing enterprise, daily doses of contaminants (DDC) - fats (daily consumption $-1500 \mathrm{~m}^{3} /$ day $\left( \pm 300 \mathrm{~m}^{3} /\right.$ day [3]) have been defined. However, fats are organic contaminants and their complete removal does not provide for the purification of the wastewater from ammonia nitrogen, phosphorus and chlorides. Therefore, it is necessary to select DDC for inorganic contaminants, proceeding from the previous research $[1,26]$, the one adopted here is the "chlorides concentration" being the most difficult contaminant to be removed.

When using combined wastewater purification systems for meat processing enterprises (DDS - fats), it was experimentally calculated [24] that as a result of the removal of such DDS, the concentration of other pollutants decreases by at least 50-95\% (depending on the initial concentrations of pollutants).

The occurrence of emergency situations in wastewater purification systems at the meat processing enterprise is due to the following:

- Slaughter above the norm (leads to significant exceedances in the concentration of fats, phosphorus, ammonium nitrogen and increased turbidity of the wastewater);

- Additional washing of the technological equipment (occurs at regular intervals and leads to significant exceedances in concentrations of synthetic surface-active substances (ssas) and turbidity of the wastewater);

- Emptying of the skin salting tanks (occurs at regular intervals and results in significant exceedances in chloride concentrations).

The implementation of the developed TS for the operation of the electrotechnology wastewater purification system, which includes electroflotocoagulation, electrolysis destruction, sorption filtration, sedimentation and hydrocycloning, has made it possible to fully meet the requirements for maximum permissible concentrations of contaminants in the wastewater of the enterprise (Figure 4).

Adjusting the equipment to meet the developed energy efficiency criterion (2) has made it possible to meet the requirements for wastewater purification quality while minimizing the resource costs - the energy efficiency criterion (2) within a period of a month (October 2016) had a deviation from zero $\pm 9,6 \%$ (including operation under uncertainty conditions caused by the effect of emergency situations) (Figure 5).

The daily wastewater amounts of minor metallurgy enterprises which require purification equal $18 \mathrm{~m}^{3 /}$ day $\left( \pm 2 \mathrm{~m}^{3 / d a y}\right)$. Following on from the use of the the working standard of the combined electrotechnology wastewater purification equipment, DDC for the wastewater of the minor metallurgy enterprise has been estimated - SPAR (Synthetic surfactants). Experimental simulation has determined that the removal of SPAR will securely remove such contaminants as ammonia nitrogen and petroleum derivatives [24].

Emergency situations can be caused by the penetration of accidental contaminants into wastewater [27]. That is why the electrocoagulator with the function of $\mathrm{pH}$-correction of alkaline solutions with subsequent neutralization of the wastewater and a sorption filter, a deaerator with electrolysis destruction and hydrodynamic intensifiers have been included into the combined electrotechnology wastewater purification system. 


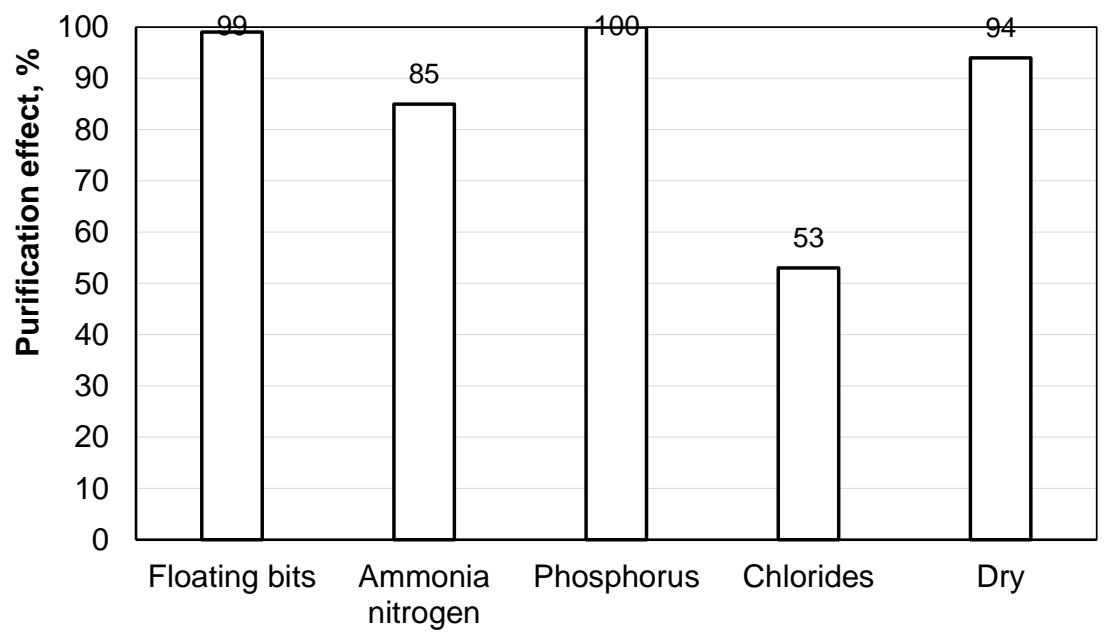

Residue

Figure 4. Efficiency of the combined electrotechnology wastewater purification (using the example of a meat processing enterprise)

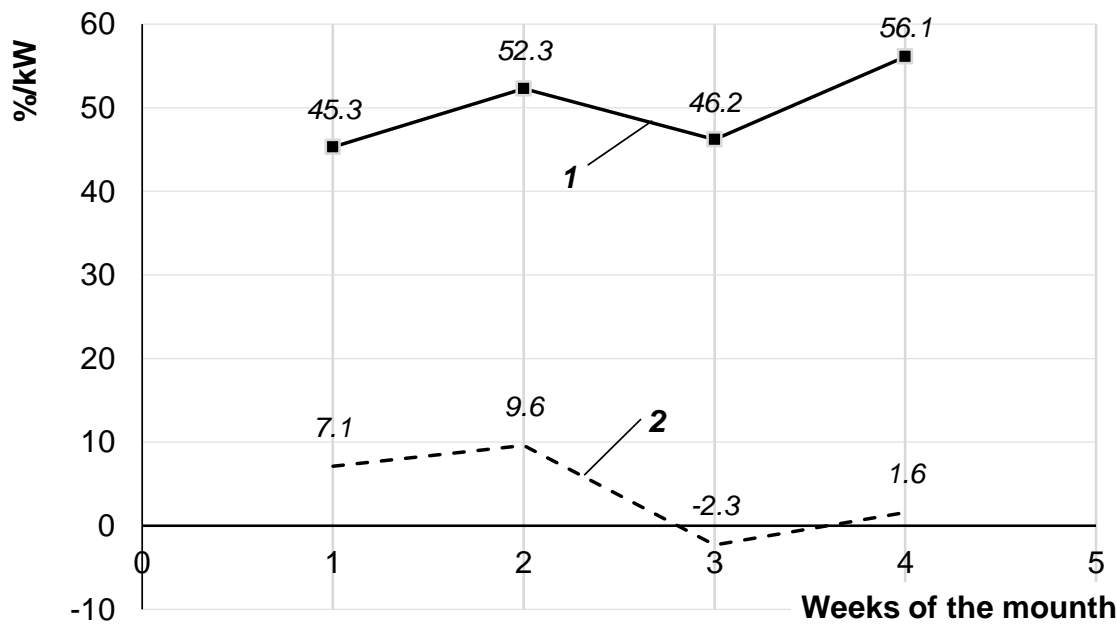

Figure 5. Comparison of the energy efficiency of the electrotechnology industrial wastewater purification (using the example of a meat processing enterprise):

1 - before implementing the control system and the technological complex (September 2016);

2 - after implementing the control system and the technological complex (October 2016)

According to the Kolmogorov (Kolmogorov-Smirnov) criterion [28], it was found that it is impossible to apply parametric approaches to the data samples obtained at the meat processing plant. The results of the work of the modeling complex of industrial water purification by the parameter of water quality "Concentration of nitrates" were selected and it was found that the significance of the results was less than $5 \%$ (actually $0,5 \%$ ). The 
statistical assessment of the data of the water passports of the studied enterprises showed that not all the obtained samples of the values of pollutants meet the requirements of the normality of the law of distribution of random variables (about $20 \%$ do not correspond). At the same time, the absence of emissions in the information received at the enterprises was established.

Applying nonparametric approaches and analyzing the results of the Mann-Whitney test for all pairs of industrial samples of approbation (Jonkhier $U$ ) statistics and the probability of accepting the hypothesis $\mathrm{H} 0(\mathrm{p})$ and the distribution of samples of energy efficiency of various reactions), we came to the conclusion that the hypothesis $\mathrm{H} 0$ is accepted (the smallest values $\mathrm{U}=46,5, \mathrm{p}=0,790953$ ), all datasets are homogeneous [28]. The results of the work of the intelligent information-functional model are acceptable and the model can be used at industrial facilities, for example, as a decision support system.

Adjusting the equipment to meet the energy efficiency criterion (2) has made it possible to meet the requirements on ensuring the quality of wastewater purification at the lowest possible energy costs (Figure 6).

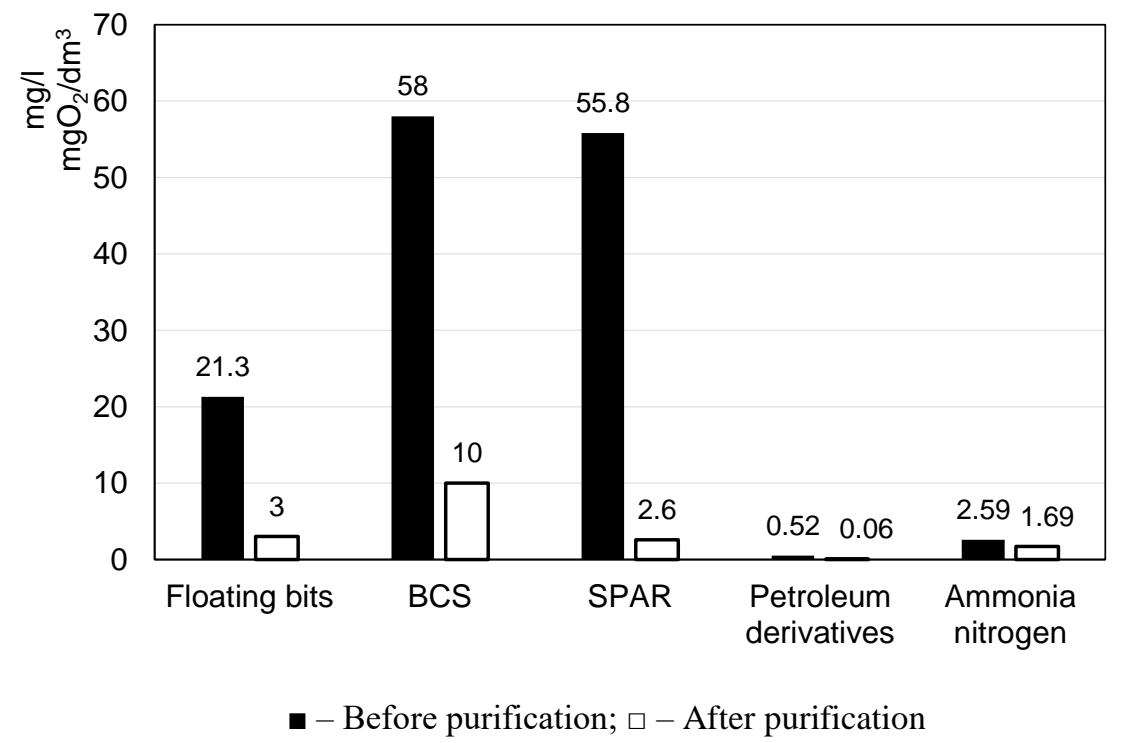

Figure 6. Combined system of electrotechnology wastewater purification (using the example of a minor metallurgy enterprise)

Production observations of the wastewater purification processes with determination of the level of energy consumption during the solar month has provided an opportunity to obtain the deviation of $E F_{Y}= \pm 3,4 \%$ (Figure 7). 


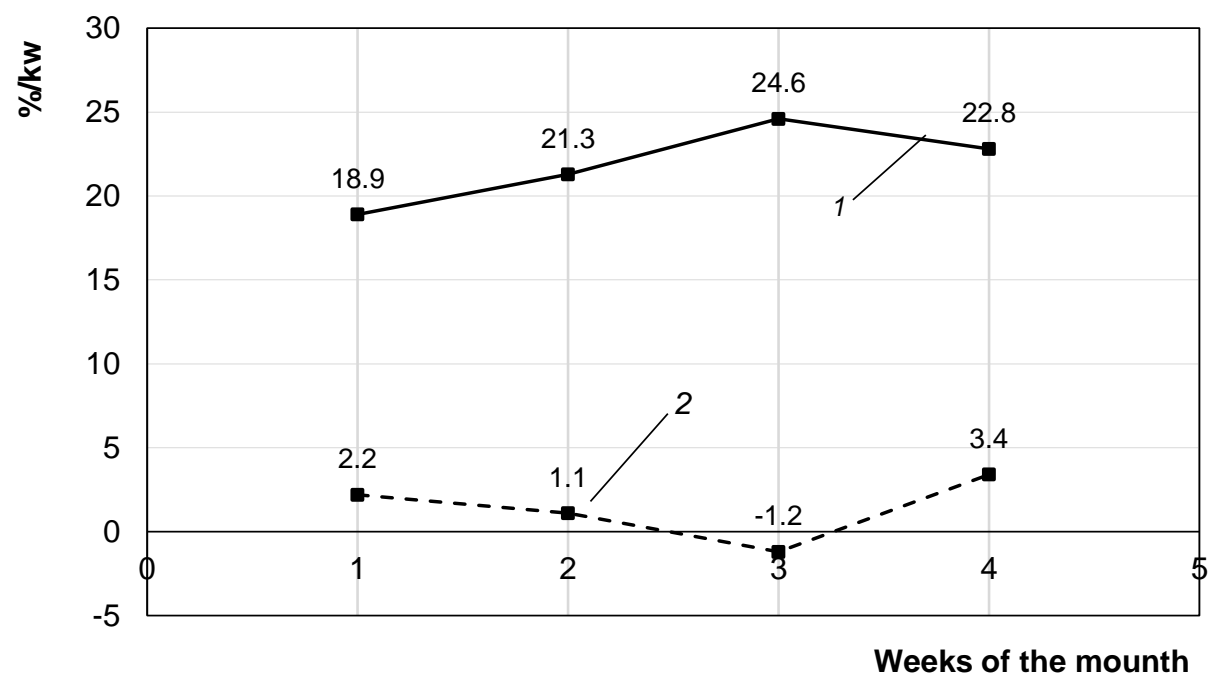

Figure 7. Comparison of energy efficiency of the electrotechnology industrial wastewater purification (using the example of a minor metallurgy enterprise):

1 - before implementing the control system and the technological complex (February 2017);

2 - after implementing the control system and the technological complex (March 2017)

After analyzing the results of the industrial implementation of the energy efficient industrial electrotechnology wastewater purification systems at meat processing and minor metallurgy enterprises, it can be stated that the improved method [26] has provided an opportunity to fulfill the ecological requirements as to the quality of the wastewater discharge while meeting the energy efficiency (2). Such industrial enterprises have also been provided with the opportunity to reuse the purified wastewater in technological processes (e.g. equipment washing and irrigation of the territory), thereby increasing the resource efficiency.

It has been confirmed that system-building elements of the advanced approaches of the TS synthesis of the combined electrotechnology wastewater purification are working standard of the combined electrotechnology wastewater purification and the DDC method (see Figure 2); at the same time, their object-oriented use is to be based on creation, as a result of systematic assessment of the objects of the wastewater discharge, the water passport. Having regard to the above, it can be claimed that not fully complying with the energy efficiency requirements (see Figs. 5 and 7), caused by an insufficiently long-lasting study of the enterprises, which were under testing, the broadening of the informative base of the major research is crucial for the improvement of the energy efficiency.

\section{Conclusions}

1. The integrated use of the improved scientific and theoretical foundations of electrotechnology management for water purification makes it possible to improve the methods of removing pollutants from aqueous solutions by comprehensively accounting for the mutual influence of methods and techniques for their elimination. 
2. The use of the advanced methods of synthesis of the TS for wastewater purification systems at continuous production has made it possible to introduce resource-saving schemes of wastewater discharge (re-use of water in technological processes).

3. Practically implemented approaches aiming at improving the creation and operation of the combined electrotechnology wastewater purification systems of continuous production have improved the energy efficiency of processing multi-component wastewater discharges: for meat processing enterprises the deviation of the energy efficiency criterion from zero makes $\pm 9,6 \%, \pm 3,4 \%$ for minor metallurgy enterprises.

4. The analysis of the results obtained from the operation of the created wastewater purification systems at the continuous production has shown that the proposed approaches to the TS synthesis give an opportunity to reduce the negative effects of the man-caused and natural emergency situations, by means of using the equipment for setting up the combined electrotechnologies of wastewater purification and taking into account the DDC method in information-functional simulation.

\section{References}

1. Goncharov F.I. (2007), Issledovanie mehanizma nakoplenija osadka na stenkah trub $\mathrm{v}$ seti vodokanala, Sovremennye problemy i puti ih reshenija v nauke, transporte, proizvodstve i obrazovanii, 20, pp. 58-67.

2. Clark N.A., Kabler P.W. (1954), The inactivation of purified coxsackie virus in water by chlorine, Am. J. Hyg., 59, pp. 119-127.

3. Bolshakov N.Yu. (2011), Modernizacija ochistnyh sooruzhenij i optimizacija udalenija biogennyh veshhestv soglasno NDT-3, Ochistka vody. Vodosnabzhenie, 7, pp. 60-67.

4. Butseva L.N., Getmantsev pp.V., Rashkovsky G.B. (2008), Jeffektivnost' ochistki promyshlennyh stochnyh vod s pomoshh'ju koaguljantov «AKVA - AURAT», Vodosnabzhenie i santehnicheskoe oborudovanie, 1, pp. 33-39.

5. Vasyljuk T.P. (2009), Vplyv ochyshhennja stichnykh vod biologhichnym metodom na roslynakh vydiv Eichornia Crassipes Martius vid riznogho ghidravlichnogho navantazhennja, Biotekhnologhija, 1, pp. 99-106.

6. Vasiljev B.V., Mishukov B.G., Solovjeva E.A. (2009), Reagentnoe udalenie fosfora iz gorodskih stochnyh vod, Vodosnabzhenie i santehnicheskoe oborudovanie, 2, pp. $58-61$.

7. Zaiets N., Shtepa V., Pavlov P., Elperin I., Hachkovska M. (2019), Development of a resource-process approach to increasing the efficiency of electrical equipment for food production, Eastern-European Journal of Enterprise Technologie, 5(8), pp. 59 65.

8. Kirijenko P.G., Varlamov E.M., Bereshko I.M. ta in. (2009), Vodopostachannja, vodovidvedennja ta jakistj vody, Kharkiv.

9. Goncharuk V.V., Maljarenko V.V., Jaremenko V.A. (2008), Vykorystannja uljtrazvuku u vodopidghotovci, Khimija ta tekhnologhija vody, 3, pp. 253-277.

10. Goncharuk V.V., Bozhko I.V., Falkovsky N.I. i t. d. (2008), Diafragmennyj razrjad i ego ispol'zovanie dlja ochistki vody, Himija $i$ vodnaja tehnologija, 5. pp. 463-477.

11. Esina E.A., Lebedeva E.A. (2010), Ghlyboka ochystka stichnykh vod pozhyvnykh rechovyn za dopomoghoju mineraljnykh reaghentiv, Voda ta tekhnologhija ochyshhennja vody, 3(4), pp. 40-42. 
12. Kawamura, pp. (2000), Integrated design and operation of water treatment facilities, John Wiley, New York.

13. Evans B. (2013), Combining Wetlands with Wastewater Treatment, The North Coast Journal Weekly.

14. Song Z., Williams C., Edyvean R. (2004), Treatment of tannery wastewater by chemical coagulation, Desalination, 164, pp. 249-259,

15. Ahmed T., Bhatti Z. A., Maqbool F. et al. (2016), A comparative study of synthetic and natural coagulants for silver nanoparticles removal from wastewater, Desalination and Water Treatment, 57, pp. 18718-18723.

16. Matilainen A., Lindqvist N., Tuhkanen T. (2005), Comparison of the effiency of aluminium and ferric sulphate in the removal of natural organic matter during drinking water treatment process, Environmental technology, 26, pp. 867-876.

17. Amagloh F.K., Benang A. (2009), Effectiveness of Moringa Oleifera seed as coagulant for water purification, African Journal of Agricultural Research, 4(1), pp. 119-123.

18. Sens M.L., Emmendoerfer M.L., Muller L.C. (2015), Water filtration through wood with helical cross-flow, Desalination and Water Treatment, 53, pp. 15-26.

19. Eikebrokk B. (1996), Removal of humic substances by coagulation, Chemical Water and Wastewater Treatment IV, Springer-Verlag, Berlin Heidelberg, pp. 173-187.

20. Halim A.A., Thaldiri N.H., Awang N., Latif M.T. (2012), Removing boron from an aqueous solution using turmeric extract-aided coagulation-flocculation, American Journal of Environmental Sciences, 8(3), pp. 322-327.

21. Farajnezhad H., Gharbani P. (2012), Coagulation treatment of wastewater in petroleum industry using poly aluminum chloride and ferric chloride, IJRRAS, 13(1), pp. 306-310.

22. El-Gohary F., Tawfik A., Mahmoud U. (2010), Comparative study between chemical coagulation/precipitation versus coagulation/dissolved air flotation for pre-treatment of personal care products wastewater, Desalination, 252, pp. 106-112.

23. Kuchta, J.M., States pp.J., McGlaughlin J.E. (1985), Enhanced chlorine resistance in tap water-adapted Legionella pneumophila as compared with agar medium-passaged strains, Applied Environmental Microbiology, 50, pp. 21-26.

24. Shtepa V.M., Vertai pp.P., Zaiets N.A. (2018), Metodychne zabezpechennja avtomatyzovanykh system vodoochystky, Vyrobnyctvo \& Mekhatronni Systemy 2018: materialy II-j Mizhnarodnoji konferenciji, pp. 38-41.

25. Ljuger Dzh.F. (2005), Iskusstvennyj intellekt: strategii i metody reshenija slozhnyh problem, Moscow.

26. Russell pp., Norvig P. (2006), Iskusstvennyj intellekt: sovremennyj podhod, Moscow.

27. Shtepa V.N. (2016), Konceptual'nye osnovy jenergojeffektivnoj sistemy upravlenija kombinirovannymi sistemami vodoochistki, Izvestija vysshih uchebnyh zavedenij $i$ jenergeticheskih obedinenij SNG, Jenergetika: nauchno-tehnicheskij zhurnal, 5, pp. 479-487.

28. Singpurwalla N.D., Wilson pp.P. (1999), Statistical Methods in Software Engineering. Reliability and Risk, Springer. 